Personalidade Acadêmica Homenageada:

Florisbal de Souza Del'Olmo (Professor Convidado - UNICURITIBA)

\title{
INCOTERMS: UMA PERSPECTIVA DE UNIFORMIZAÇÃO DA REGULAMENTAÇÃO DO COMÉRCIO INTERNACIONAL
}

\section{INCOTERMS: A PERSPECTIVE OF UNIFORMIZATION OF THE REGULATION OF INTERNATIONAL TRADE}

\section{ELLEN GALLIANO DE BARROS}

Mestranda em Direito Empresarial e Cidadania pelo Centro Universitário Curitiba UNICURITIBA.

\section{RESUMO}

O presente estudo pretende analisar a importância do Incoterms como modelo da unificação da regulamentação que trata do comércio internacional, diante do cenário marcado pela globalização socioeconômica e do avanço tecnológico. Nesta perspectiva, cumpre destacar a evolução do comércio internacional acompanhado do desenvolvimento das formas contratuais de compra e venda internacional, de modo a analisar o nascimento da Lex mercatoria, durante a Idade Média, até chegar as influências da atual Era da mundialização com o aprimoramento das práticas mercantis. Assim, a Lex mercatoria, conjunto de regras criado pelos próprios mercadores com base nos usos e costumes, tem recebido nova roupagem, a partir da inclusão de novas fontes, tendo em vista a pretensão de unificação do regramento que abarca as transações comerciais entre os países. Por este motivo, o objetivo central do artigo é a exibição do Incoterms, que é caracterizado por termos internacionais empregados no contrato de prática mercantil, desenvolvido por organização internacional não governamental, com propósito de facilitar a exportação e importação de bens, reduzir os custos do negócio jurídico, afastar obstáculos para o crescimento econômico dos Estados e, acima de tudo, eliminar as incertezas da legislação aplicável a cada caso e as divergências entre as partes. 


\section{Personalidade Acadêmica Homenageada:}

\section{Florisbal de Souza Del'Olmo (Professor Convidado - UNICURITIBA)}

Entretanto, embora o instituto em comento demonstre a harmonização do regramento sobre a mercancia exterior, merece implementação e melhoria em seu conteúdo, a fim de traçar todas as situações fáticas que podem ocorrer no momento da execução do contrato, sem ser visto tão somente como uma cláusula contratual sem autonomia jurídica necessária. Isto posto, o foco direciona-se ao estudo do contexto marcado, de um lado, pela emergência da harmonização das regras influenciadas pela Globalização e, por outro lado, pela aparição do Incoterms, nos moldes da nova Lex mercatoria, que ainda não possui a devida força de aplicação. Nesse sentido, o procedimento metodológico utilizado é o dedutivo-indutivo, em virtude da investigação do problema com suporte doutrinário e jurisprudencial.

PALAVRAS-CHAVE: Comércio Internacional; Unificação das Regras; Incoterms.

\section{ABSTRACT}

The present study intends to analyze the importance of Incoterms as a model of the unification of the regulation that deals with the international trade, in the scenario marked by socioeconomic globalization and the technological advance. In this perspective, it is important to highlight the evolution of international trade, accompanied by the development of contractual forms of international buying and selling, in order to analyze the birth of Lex mercatoria during the Middle Ages until the influences of the current era of globalization and the improvement of market practices. Thus, Lex mercatoria, a set of rules created by the merchants themselves on the basis of customs and customs, has been given new coverage, from the inclusion of new sources, with a view to the unification of the regulation that covers commercial transactions between countries. For this reason, the central objective of the article is the exhibition of Incoterms, which is characterized by international terms used in the commercial practice contract, developed by international nongovernmental organization, with the purpose of facilitating the export and import of goods, reduce costs of the legal transaction, to remove obstacles to the economic growth of the States and, above all, to eliminate the uncertainties of the legislation 


\section{Personalidade Acadêmica Homenageada:}

\section{Florisbal de Souza Del'Olmo (Professor Convidado - UNICURITIBA)}

applicable to each case and the differences between the parties. However, although the institute in question demonstrates the harmonization of the regulation on external merchandise, it deserves implementation and improvement in its content, in order to trace all the factual situations that may occur at the time of contract execution, without being seen as only one contractual clause without the necessary legal autonomy. The focus, therefore, is on the context, on the one hand, of the emergence of the harmonization of rules influenced by Globalization and, on the other hand, on the appearance of Incoterms, along the lines of the new Lex mercatoria, which does not yet have the application force. In this sense, the methodological procedure used is deductive-inductive, due to the investigation of the problem with doctrinal and jurisprudential support.

KEYWORDS: International Trade; Unification of the Rules; Incoterms.

\section{INTRODUÇÃO}

O presente estudo tem por objetivo examinar, com base na doutrina e em julgados internacionais, a importância do Incoterms, diante do cenário que revela a urgência de harmonização da regulamentação que trata do comércio internacional, por influência do processo de Globalização e da inovação das práticas de exportação e importação.

A história econômica apresenta a evolução das formas de transação comercial, em especial, desde a derrocada do Feudalismo, o que também propiciou o aprimoramento dos negócios jurídicos e seus regramentos. De início, surgem as diretrizes elaboradas pelos próprios mercadores, com fundamento nos usos e costumes, configurando, assim, a Lex mercatoria. Após, sobrevieram às leis nacionais, transferindo a regulamentação para as mãos dos Estados Soberanos.

Contudo, em razão das várias leis soberanas, que poderiam ser aplicadas a cada caso, permaneceram as dificuldades entre os vendedores e compradores, no que se refere às divergências nas interpretações legais, ausência de cláusulas sobre 
Personalidade Acadêmica Homenageada:

Florisbal de Souza Del'Olmo (Professor Convidado - UNICURITIBA)

situações ocorridas durante a execução contratual e qual seria a lei mais adequada para regrar o negócio jurídico. Ocorreram, então, as principais regras de conexão do Direito Internacional Privado. Porém, o processo de globalização induziu à desterritorialidade e à privatização dos regramentos, fazendo com que as leis nacionais e as diretrizes elaboradas pelos mercadores fossem direcionadas à unificação dos regulamentos e à origem não governamental.

Nesta toada, os Incoterms, definidos como termos internacionais do comércio, aparece como novo modelo da Lex mercatoria, buscando a padronização e harmonização de preceitos normativos do comércio exterior. Para mais, objetiva a redução dos custos de importação e exportação, além do afastamento de interpretações legais distintas que, na maior parte, são obstáculos para o sucesso da compra e venda de bens. No entanto, embora o instrumento concretize a pretensão de unificação de regimentos, aperfeiçoe o procedimento mercantil e seja aplicado automaticamente em alguns países, permanece, na maioria dos Estados, como mera cláusula contratual, isto é, sem a força de aplicação automática. Deste modo, se faz urgente o aperfeiçoamento da sua estrutura e de seu conteúdo.

Por tudo isto, o artigo tratará da evolução do comércio exterior, suas formas contratuais e regramentos, na sequência, serão trabalhadas as peculiaridades da Lex mercatoria, com seus aspectos conceituais, históricos e as novas roupagens. Ao final, as particularidades do Incoterms serão apresentadas, respectivamente, seu histórico, suas pretensões, termos abreviados e melhorias necessárias, tudo isto voltado à perspectiva de unificação dos sistemas relativos ao comércio internacional.

\section{COMÉRCIO INTERNACIONAL E SEUS REGULAMENTOS}

A doutrina define comércio internacional como a troca de bens e serviços, entre indivíduos, empresas e governos, para além de territórios e fronteiras dos países, tendo como base a satisfação das necessidades e, de outro lado, a finalidade de lucro (PIRES, 2001, p. 02). No entanto, para entender melhor suas bases atuais e o desenvolvimento de suas formas ao longo dos anos, vale analisar a 


\section{Personalidade Acadêmica Homenageada:}

\section{Florisbal de Souza Del'Olmo (Professor Convidado - UNICURITIBA)}

sua evolução histórica, a seguir.

Anteriormente ao período marcado pela intensificação comercial que deu surgimento aos burgos e representou a derrocada do Feudalismo, as práticas mercantis já existiam por meios mais simples, com caráter de subsistência da população, da mesma forma, eram realizados por meio da troca, sem a existência e a utilização de moedas e outras formas de pagamento, como ensina Huberman (1980).

Com o passar dos anos, devido às Cruzadas (séculos XI e XIII) o comércio que antes era local, expandiu-se, uma vez que se criaram novas rotas de comércio entre Europa e Oriente, além da criação de cidades próprias para a mercantilização, como, por exemplo, Veneza, Constantinopla, Gênova e Pisa (AMARAL, 2006, p. 71). Nesse cenário, a população migrou do campo para a cidade (estabelecida em burgos), passou a reivindicar mais direitos, liberdades e garantias individuais, na mesma ocasião, apareceram as corporações de comerciantes, as quais reivindicavam mais proteção de direitos e melhores salários.

Ademais, o intercâmbio do dinheiro e outros modelos de transação financeira foram desenvolvidos, tornando possível a presença de vários mercados. O período, portanto, expressava os ideais de liberdade da classe dos comerciantes e dos camponeses. Os membros das corporações/ ligas expressavam o monopólio do comércio das cidades e a negociação de mercadorias, aliás, foi o marco inicial para criar regulamentos privados que fixavam a obediência dos mercadores aos códigos, o preço do produto, formas de concorrência e de inspeção dos bens comercializados. Era a crescente da Lex mercatoria (século XVII).

Sobreveio a expansão mercantil para a Europa Ocidental, em razão do aproveitamento de terras inutilizadas, fator este, que também favoreceu 0 alargamento do comércio exterior. De mais a mais, registra-se que devido ao monopólio das corporações de ofício, várias condutas excessivas foram realizadas, como o preço abusivo da mercadoria, o que fez com que o Estado fiscalizasse as transações comerciais.

$\mathrm{Na}$ sequência, outras rotas mercantis foram estabelecidas, desta vez, nos países da costa atlântica, o que favoreceu o descobrimento dos continentes Africano 


\section{Personalidade Acadêmica Homenageada:}

\section{Florisbal de Souza Del'Olmo (Professor Convidado - UNICURITIBA)}

e Americano. O período de expansão industrial subsequente fez surgir a Era do Capitalismo, que revelava a divisão de trabalho com a intensa mão de obra de assalariados, dentro de uma estrutura doméstica, aqui, as antigas corporações e suas regras foram praticamente derrubadas (HUBERMAN, 1980, p. 167).

Em seguida, surgem os primeiros sinais do Liberalismo, de crítica ao Mercantilismo, descrevendo ideais da não intervenção estatal na economia, por meio da redução de impostos, incentivos à indústria, comércio livre e ausência de limitações. Pretendia, além disto, o descenso dos monopólios e o acúmulo dos metais preciosos, mediante a circulação do dinheiro. O marco deste movimento foi a Revolução Francesa (1789), significando a conquista de direitos e liberdades individuais.

Contudo, em virtude da restrição de terras à população de baixa renda e aumento dos preços de arrendamento, muitas pessoas viviam em condições de miséria e em total desemprego. Por este motivo, passaram a vender a sua força de trabalho e, consequentemente, submetiam-se às más condições de serviço. $\mathrm{O}$ novo método econômico e seus resultados foram evidenciados em todos os países, sobretudo na Inglaterra. Após, elevou-se o número de desempregados, à vista da substituição do trabalho manual por máquinas, fato que também provocou a diminuição dos salários (HUBERMAN, 1980, p. 187).

Se por um lado o contexto representava o desenvolvimento socioeconômico intenso das indústrias, em razão de apenas um grupo alcançar o lucro, por outro lado, este lucro era gerado em detrimento da má qualidade de vida dos trabalhadores e da submissão às condições inadequadas de trabalho.

Em contrapartida aos resultados negativos, as primeiras doutrinas socialistas surgiram, indicando a necessidade da melhoria das condições de vida da classe proletária, uma sociedade planificada e que os meios de produção fossem de propriedade do povo. Era, assim, o enfraquecimento da supremacia dos burgueses (comerciantes e industriais), além da conquista do poder político.

O final do século XIX expressava, então, o drástico Capitalismo Moderno, que apresenta grande concentração de capitais nas mãos dos banqueiros, entretanto, apesar de haver um regulamento baseado na "Oferta e Procura", um 


\section{Personalidade Acadêmica Homenageada:}

\section{Florisbal de Souza Del'Olmo (Professor Convidado - UNICURITIBA)}

número alto de mercadorias permanecia nas fábricas, sem a possibilidade de compra. A solução mais cabível seria de realizar o comércio exterior, isto é, os produtos excedentes seriam vendidos nas colônias, com a sujeição delas aos países mais ricos, por meio do domínio das matérias-primas locais. Deste modo, nasce o Imperialismo, consistente na ampliação do fluxo de riqueza excedente e motivação de desenvolvimento de países atrasados.

O momento exibe a superprodução pretendendo a subsistência da população interna e externa, a acentuação das transações comerciais, das matériasprimas e da força de trabalho, todavia, a produção ocorria tão somente quando os empresários estivessem certos do lucro. Dessarte, quando o lucro despencava, a crise era instaurada.

Em contraposição à ideologia capitalista, alguns Estados adotaram a postura socialista, como a Rússia, durante a Revolução dos Bolcheviques. Era um Estado fundado na economia planificada e com esforço de todos os cidadãos para o bem da coletividade, bem-estar e segurança máxima. O responsável pelo sustento, saúde e educação de toda a comunidade russa seria organismo estatal, logo, tinha o poder da tomada das decisões, era detentor do lucro decorrente das atividades econômicas, inclusive fazia o controle do comércio internacional (HUBERMAN, 1980, p. 225).

No entanto, em 1929 aparece a crise das grandes potencias, tornando emergente a busca de soluções para resolver o caos econômico. Assim, as saídas recaiam na abolição das produções, através de um pagamento feito aos produtores, com vistas ao retorno do lucro aos grandes empresários, para além, indicavam a insubordinação das grandes propriedades a toda a sociedade e a não distribuição de renda entre as classes.

Neste contexto, após a criação do Fascismo e do Nazismo, os empresários que enfrentavam a crise recorreram aos adeptos dos movimentos totalitários em troca de favores futuros. Embora os dois regimes apresentassem uma aparência socialista, na prática, prendiam e exterminavam pessoas ligadas ao coletivismo, confiscavam bens, reduziam salários, bem como destruíam sindicatos e, por via de consequência, protegiam alguns capitalistas. 


\section{Personalidade Acadêmica Homenageada:}

\section{Florisbal de Souza Del'Olmo (Professor Convidado - UNICURITIBA)}

As duas grandes guerras delinearam a pobreza sofrida pela população mundial, as guerras armamentistas, a concorrência econômica, a manutenção da propriedade privada e a ânsia pelo lucro, especialmente na Europa.

Mais a frente, nota-se a chegada da Era da Globalização (segunda metade do século $\mathrm{XX}$ ), dando início ao acelerado avanço tecnológico dos meios de comunicação e das formas de comércio, que resultou na complexidade da relação entre pessoas e países. Outros aspectos relevantes deste novo processo seriam a superprodução das empresas que, ora busca suprir as necessidades básicas da população mundial, ora tendem a utilizar mecanismos publicitários a fim de tornar frenético o consumo pelos indivíduos, porém sempre caminhando no sentido da maximização dos lucros.

Outro ponto a ser destacado é a fluidez e a elasticidade dos contratos de comércio, dada a rápida mutação das transações mercantis ao longo do tempo, deixando de ocorrer apenas no âmbito nacional, o que leva ao caráter transfronteiriças atividades e negócios jurídicos. Aliás, acerca da questão da territorialidade, a Globalização define uma Era que marca a interdependência entre os povos, de modo a desaparecer as fronteiras de cada país, vale dizer, que as corporações transnacionais são as protagonistas dos processos e integração socioeconômica, pois partem do princípio da ausência do dever de lealdade a algum Estado-Nação, pois são estruturadas em territórios de maiores vantagens para a expansão de suas atividades (CARVALHO; SILVA, 2000, p. 244).

Para além da integração política e econômica das nações, da expressividade das empresas transnacionais, do progresso tecnológico em áreaschave, Rosseti (2014, p. 849-850) assinala a presença da desregulamentação e liberalização nas políticas públicas, como mais um dos pré-requisitos da Globalização, de forma que os países optem pela abertura do comércio, em vez de adotar somente mecanismos protecionistas.

Ora, a história evidencia que tanto as práticas mercantis, como os contratos de comércio internacional e seus regulamentos evoluíram em conjunto. O primeiro afastou-se da natureza inicial simples, que se baseava na troca e tinha como foco a subsistência da população. Trata-se, hoje, do comércio exterior, com influência da 


\section{Personalidade Acadêmica Homenageada:}

\section{Florisbal de Souza Del'Olmo (Professor Convidado - UNICURITIBA)}

globalização econômica.

O segundo, por sua vez, expressa a manifestação de vontade de duas ou mais partes, com a intenção de manter relação de serviço ou patrimonial, e mais, resguarda os princípios internacionais do Direito Internacional Privado (autonomia da vontade, pact sunt servanda e boa-fé). Também é definido pelo intercâmbio de mercadorias, capitais e serviços entre empresas de diferentes países, em que uma das partes realiza papel no meio econômico internacional.

Ainda, possui efeitos que recaem sobre todos os membros do mercado de serviços e bens. Esta modalidade de contrato interfere nos interesses corporativos de todas as empresas que participem da transação, por último, estão alinhados a algumas particularidades, tais como a arbitragem, a unificação da terminologia e a homogeneidade das disposições (VICENTE, 2003, p. 34).

O contrato exterior recebe, agora, a influência do momento que expressa a desterritorialidade (NETO, 2010, p. 34) e, deste modo, deve ser elástico e flexível, visando fixar situações comerciais novas e complexas, e não apenas, como também estar adequado às mudanças advindas do avanço tecnológico que recai nas atividades de exportação e importação.

Acrescente-se, neste cenário, a perspectiva e o desejo de harmonização/ unificação das fontes de regulamentação do comércio internacional, à vista da rápida mutação das transações desenvolvidas entre países, além da insuficiência das leis nacionais que, em sua maioria, são obstáculos para as transações exteriores e para o crescimento nacional.

Logo, como um dos produtos desta pretensão, gradualmente, surgem regras elaboradas por particulares e, de sobremaneira, por organizações internacionais não-governamentais, que estipulam, de forma robusta, várias condições para a eficiência e a facilitação das transações mercantis, embora o Estado atue como fiscal do negócio jurídico e protetor das partes, a partir da imposição de normas imperativas e princípios que devem ser respeitados no contrato.

Nesta toada, novas fontes da Lex mercatoria são evidenciadas, de modo a conservar o direito baseado em usos e costumes, criado por entes e pessoas privadas, como comerciantes e organizações internacionais de proteção à atividade 


\section{Personalidade Acadêmica Homenageada:}

\section{Florisbal de Souza Del'Olmo (Professor Convidado - UNICURITIBA)}

comercial, no entanto, recentemente, possui uma vertente supranacional, com vistas à eliminação de barreiras, para o sucesso das compras e vendas e ao afastamento das interpretações diversas de cláusulas de contrato e da legislação aplicável.

\section{LEX MERCATORIA}

A Lex mercatoria é conceituada como um conjunto de regras criado pelas corporações de ofício, durante a Idade Média, a fim de reger a relação entre os comerciantes e também as operações mercantis. Inclusive, as ligas dos mercadores possuíam tribunais internos para tratar de eventuais descumprimentos e aplicação de medidas coercitivas, como aduz Cárnio (2009, p. 151).

O regramento construído pelos mercadores apresentava caráter costumeiro, ademais, era um direito autônomo em relação aos direitos nacionais, até porque, naquele momento, os Estados encontravam-se enfraquecidos, diante do crescimento do comércio, que era de monopólio das corporações, fator que propiciou a derrocada do Feudalismo (ROMERO, 1991, p. 17).

Tem-se, portanto, que as trocas de bens e serviços foram regidas pelas regras e costumes dos entes próprios do comércio, entre os séculos $\mathrm{V}$ e XIV. Posteriormente, os Estados Nacionais passaram a intervir na regulamentação comercial, de modo a codificar tais normas, em detrimento da decadência das sociedades corporativas e, por outro lado, o fortalecimento do conceito de EstadoNação.

Em seguida, especificamente entre os séculos XVIII e XIX, destaca-se a tendência codificadora, pois os Estados soberanos tomam as rédeas do direito comercial, logo, o período foi marcado por uma perspectiva de democratização estatal e aumento de sua representatividade (CARNIO, 2009, p. 152).

Com isto, surge o embate entre Estados, uma vez que mais de um ordenamento podia ser aplicado na mesma relação jurídica, já que ambos são soberanos. Dado o conflito de leis no espaço, o Direito Internacional Privado estipulou as primeiras normativas de conexão, a fim de superar a problemática da lei aplicável.

Como se viu anteriormente, o mundo enfrentou a primeira crise capitalista 


\section{Personalidade Acadêmica Homenageada:}

\section{Florisbal de Souza Del'Olmo (Professor Convidado - UNICURITIBA)}

pela superprodução, no início do século $X X$, o que levou à nova roupagem das atividades mercantis. Todavia, a segunda metade do século XX apresentou outras alternativas de harmonização estatal, assim, nasceram as primeiras organizações internacionais não-governamentais, institutos de uniformização das legislações e associações de classe (ENGELBERG, 1997, p. 28).

Considerando a globalização socioeconômica, que influenciou a reformulação do contrato de comércio exterior, surge a necessidade da supranacionalidde, vale dizer, da existência de um ente com personalidade jurídica de direito internacional, com a capacidade de estabelecer normas comerciais aplicáveis a todos os Estados membros. A lógica, desta forma, é fundada na substituição das regras internas por um sistema baseado nos princípios gerais do Direito Internacional, isto é, a nova Lex mercatoria. De acordo com Amaral (2006), esta é constituída a partir da elaboração de leis uniformes, leis modelo, conjunto de regras e princípios que regem as transações comerciais internacionais.

Então, tendo em vista a supremacia da vontade dos particulares e da prática reiterada do comércio externo sobre as leis nacionais e restrições impostas por ela (AMARAL, 2006, p. 72), especialmente a pretensão de facilitar o comércio internacional, por meio da eliminação de divergências acerca das cláusulas de contrato e das diversidades de sistemas jurídicos aplicáveis, aliados à necessidade de reduzir gastos de importação e exportação, a atual Lex mercatoria inclui fontes direcionadas aos princípios de aceitação internacional, aos usos e instrumentos da prática mercantil. (NETO, 2010, p. 181).

A título de exemplo, as recentes fórmulas da lei de comércio apontam, em primeira posição, regras e princípios, que não precisam de aprovação dos Estados e são empregados nos contratos de eficácia imediata. Nestes moldes, figuram os Princípios Relativos aos Contratos de Comércio Internacional (1994), publicados pela UNIDROIT (Instituto Internacional para a Unificação do Direito Privado), que demonstram flexibilidade e praticidade, bem como refletem a tendência da transnacionalidade do direito (NETO, 2010, p. 189).

Em segundo plano, aparecem os tratados e convenções, os quais são transformados em leis nacionais, cumprindo a função normativa e de harmonização 


\section{Personalidade Acadêmica Homenageada:}

\section{Florisbal de Souza Del'Olmo (Professor Convidado - UNICURITIBA)}

do direito, para que seja garantida a segurança dos negócios jurídicos. São acordos internacionais regidos pelo Direito Internacional, que é concluído por escrito entre um ou mais Estados, ou uma ou mais organizações internacionais, ou, ainda, somente entre organizações internacionais. Tem-se, como exemplo, a Convenção de Roma sobre a Lei Aplicável às Obrigações Contratuais (1991), além da Convenção das Nações sobre Contratos de Compra e Venda Internacional de Mercadorias (2010). Esta representa a principal regulação do contrato internacional referente à compra e venda internacional em procedimento arbitral, uma vez que é o único documento legal sobre a temática com aceitação mundial.

Em terceiro lugar, cabe registrar que as decisões arbitrais presididas pelas organizações internacionais não-governamentais também são fontes da nova Lex mercatoria, pois possuem ampla utilização no plano internacional, atendem as necessidades de um direito autônomo e estão alinhadas aos usos e costumes, sem gerar entraves, quando do decisório arbitral (ARAUJO, 2003, p. 415). A arbitragem é o caminho mais aceito, em decorrência das vantagens às partes, como a celeridade na solução dos conflitos, a especialidade dos árbitros e o sigilo das sentenças (CARNIO, 2009, p. 133).

A adoção deste meio de resolução de conflitos tem crescido gradualmente, dada a demanda das partes pela previsibilidade, segurança, velocidade, flexibilidade, neutralidade e eficácia do negócio jurídico. Mais que isto, a arbitragem representa um procedimento célere, com menos rigorismos processuais e composto por técnicos especialistas da área em discussão.

No mesmo sentido da arbitragem, existe a Lei Modelo da UNCITRAL (Comissão das Nações Unidas sobre o Direito do Comércio Internacional), a qual regula os aspectos das decisões de arbitragem, com a finalidade incentivar cada Estado a adotar e incorporar este mecanismo de resolução de conflitos no seu sistema jurídico.

Destaca-se, além do mais, o instrumento denominado "Contratos-tipo", os quais são cláusulas padronizadas que estipulam direitos e obrigações às partes. A natureza do instituto é contratual, afastando-se do valor de norma jurídica. São exemplos os contratos de venda internacional de grãos, contratos formulados por 


\section{Personalidade Acadêmica Homenageada:}

\section{Florisbal de Souza Del'Olmo (Professor Convidado - UNICURITIBA)}

associações de comerciantes e produtores, contratos ligados aos interesses das indústrias mecânicas, elétricas, eletrônicas e metalúrgicas (NETO, 2010, p. 203).

Por derradeiro, aparece o Incoterms, também com a pretensão de reduzir incertezas, inseguranças causadas pelas leis nacionais e os desentendimentos contratuais.

\section{INCOTERMS: FONTE DA NOVA LEX MERCATORIA}

Nesta perspectiva recente da Lex mercatoria, do aprimoramento de suas fontes, em razão das influências da Era da Globalização aliadas às políticas neoliberais e à pretensão de uniformização do direito acerca das relações comerciais, aparece o instituto do Incoterms, como modelo de regulação privada.

Significa dizer, em outras palavras, que o Incoterms figura como uma das fontes da nova Lex mercatoria, pois são termos internacionais do comércio criados pela Câmara Internacional do Comércio (CCI), de Paris, em 1936, que fixam um padrão de regras neutras a ser adotado a fim de harmonizar as condições de venda internacional (NETO, 2010. p. 211). Quer dizer, os termos exteriores estipulam deveres e obrigações mínimas entre vendedor e comprador, bem como possíveis riscos de prejuízos decorrentes do comércio realizado.

Tais previsões foram resultados de vastas pesquisas feitas sobre a prática mercantil entre países, durante a década de 20. No início deste período, a organização mundial deu início ao trabalho voltado aos termos comerciais utilizados nos contratos de compra e venda, então, a $\mathrm{CCl}$ fez um estudo de cláusulas habitualmente empregadas em 13 países. No entanto, apenas em 1923 os resultados foram publicados, os quais apontaram divergências na interpretação (CÂMARA INTERNACIONAL DO COMÉRCIO, 2018).

Já no ano de 1928, à vista da discrepância da pesquisa inicial, foi realizado um estudo mais amplo, buscando examinar os termos comerciais utilizados em mais de 30 países. A conclusão deste trabalho foi publicada somente em 1936, dando origem à primeira versão dos Incoterms, que incluiu as seguintes abreviaturas: FAS, FOB, C e F, CIF, Ex Ship e Ex Quay.

Posteriormente, tendo como base o crescimento do transporte ferroviário, à 


\section{Personalidade Acadêmica Homenageada:}

\section{Florisbal de Souza Del'Olmo (Professor Convidado - UNICURITIBA)}

vista da Segunda Guerra Mundial, em 1953 surgiu a primeira revisão das regras do Incoterms. Neste momento, apareceram três diferentes termos de comércio voltados ao transporte não marítimo, quais sejam: o DCP (Delivered Costs Paid), o FOR (Free on Rail) e o FOT (Free on Truck).

Passados alguns anos, especificamente em 1967, a Câmara Internacional do Comércio procedeu à terceira versão do Incoterms, tendo como foco principal a correção de interpretações equivocadas da edição anterior. Nesta toada, foram lançadas dois novos termos mercantis, relativos à entrega do produto comercializado no endereço da fronteira (DAF) e à entrega no destino (DDP).

Em 1974, em virtude do crescimento do transporte aéreo, criou-se a quarta edição do instrumento em exame, de forma a inserir um dos termos mais conhecidos, respectivamente, o FOB Airport (Free on Board Airport). Sobreveio, na década de 80, a crescente do transporte por meio de contêineres e o avanço dos processos de documentação, o que propiciou a criação de outra alteração das redações comerciais. Fora isto, deu margem à criação do termo FRC (Free Carrier....Named at Point), que estipulava a questão de bens não recebidos pelo lado do navio, isto é, que seriam recebidos em terra, como, por exemplo, um pátio de contêineres.

Na sequência, aconteceu a revisão completa do Incoterms (1990), dando início a quinta modificação, que tanto simplificou o prazo da Free Carrier, quanto eliminou regramentos particulares de transporte, para o FOR, Free on Rail, FOT, Free on truck e FOB Airport, além do Free on Board Airport. Neste aspecto, a exclusão de tais diretrizes representou a inclusão de todos os termos referentes ao transporte de mercadorias no termo geral FCA (Free Carrier... no Named Point).

De mais a mais, com a chegada do século $X X I$, a versão anterior foi alterada, a fim de conter na redação dos termos internacionais a seção denominada "Licença, Autorizações e Formalidades" do FAS e DEQ Incoterms. Objetivou, deste modo, atender o modelo de tratamento feito pelas autoridades alfandegárias acerca de questões referentes ao exportador e ao importador registrado.

A atual edição, datada de 2010, caracteriza a consolidação da família "D" das regras do Incoterms, bem como a exclusão dos seguintes termos: DAF 


\section{Personalidade Acadêmica Homenageada:}

\section{Florisbal de Souza Del'Olmo (Professor Convidado - UNICURITIBA)}

(Delivered at Frontier), DES (Delivered Ex Ship), DEQ (Delivered Ex Quay) e DDU (Delivered Duty Unpaid). Por outro lado, exibe os novos termos, como o DAT (Delivered at Terminal) e o DAP (Delivered no lugar). Também, nesta oportunidade, foi incluída a obrigação de cooperação em compartilhar dados entre as partes e mudanças para acomodar as chamadas "vendas de sequência de caracteres".

Por fim, diante da tendência de intensificação de um comércio globalizado, o que se tem hoje é a construção da futura versão da regulação privada da mercancia internacional, que possivelmente será publicada em 2020. Tal edição conta com o auxílio de advogados, comerciantes e representantes de empresas de ramos variados ao redor do mundo.

Pois bem. Diante da redação da edição vigente (2010), oportuno registrar os quatro grupos que estabelecem os termos internacionais, quais sejam: grupo $\mathrm{E}$ (contrato de partida); grupo F (transporte pago no destino); grupo C (contrato de transporte principal pago na origem); e grupo $D$ (contrato de chegada).

O grupo E contém apenas a cláusula Ex Works (EXW), que significa "a partir do local da produção". Trata-se da cláusula que fixa a obrigação do vendedor/exportador de entregar a mercadoria nas instalações do vendedor ou em outro local requerido. Com o emprego deste termo, as partes acordam que os encargos financeiros e as responsabilidades advindas da aquisição das mercadorias são de exclusividade do transportador. Ademais, a responsabilidade por danos causados aos produtos ou perda deles, após a saída da instalação do vendedor, é destinada ao comprador (AMARAL, 2006, p. 274).

No que tange ao grupo $F$, aponta-se, em primeira mão, o termo de Free Carrier (FCA), "Operador gratuito", que dispõe sobre a obrigação do exportador de entregar as mercadorias com o pagamento de todas as taxas e impostos, no local determinado pelo comprador. Por outro vértice, cabe ao importador arcar com os riscos de perda ou danos às mercadorias, desde o momento que são entregues pelo exportador e, ainda, é responsável pelo transporte principal dos produtos e outras despesas.

O Free Alongside Ship (FAS), "Livre ao lado do navio", trabalha com a noção da responsabilidade do vendedor por todas as despesas necessárias à exportação 


\section{Personalidade Acadêmica Homenageada:}

\section{Florisbal de Souza Del'Olmo (Professor Convidado - UNICURITIBA)}

até a ocasião em que os produtos estejam prontos para embarque no navio estabelecido pelo comprador, também fica responsável pelo desembaraço das mercadorias para exportação. O importador é responsável pelos riscos do transporte até a local de chegada.

Na sequência, o Free on Board (FOB), "Livre a bordo", aduz a entrega dos produtos pelo exportador a bordo do navio determinado pelo importador. O primeiro indivíduo arca com os custos devidos ao desembaraço dos bens, bem como é responsável por zelar dos artigos, enquanto estão a bordo. O comprador cuida dos custos desde o embarque das mercadorias.

De outro lado, existe o grupo $\mathrm{C}$, exibindo cláusulas sobre a responsabilidade do exportador quanto ao transporte principal, ficando a cargo do comprador o desembaraço aduaneiro dos produtos no país. A cláusula do Cost and Freight (CFR), "Custo e Frete", trata da entrega das mercadorias ao porto de destino pelo vendedor, que também tem a responsabilidade de contratar e pagar os custos e o frete do transporte. Ao importador, neste caso, cabe o pagamento dos gastos da chegada das mercadorias.

Ainda sobre o mesmo grupo, consta o termo Cost, Insurance and Freight (CIF), "Custo, seguro e frete", que aponta a responsabilidade do vendedor em pagar os custos do transporte do produto até o porto, o desembaraço aduaneiro, custos de armazenagem, embarque e transporte principal. Ao passo que o comprador é encarregado dos custos e riscos aos produtos, desde o desembarque.

Além do mais, a cláusula Carriage Paid to (CPT), "Transporte pago a", esboça que o exportador é incumbido da entrega das mercadorias ao transportador ou a outro indivíduo determinado por ele próprio. Na mesma senda, o vendedor tem a obrigação de contratar e pagar os gastos necessários do transporte até o destino final.

O último termo do grupo $\mathrm{C}$ é o Carriage and Insurance Paid to (CIP), "Transporte e Seguro Pago", que aborda a questão da obrigação do vendedor de arcar com todos os custos referentes à mercadoria, inclusive pagamento de seguro pelo transporte, até a chegada ao local de destino. Já o importador, fica responsável pelos custos e danos, após o recebimento dos bens comercializados. 


\section{Personalidade Acadêmica Homenageada:}

\section{Florisbal de Souza Del'Olmo (Professor Convidado - UNICURITIBA)}

Enfim, o grupo D prevê cláusulas sobre a responsabilidade do exportador até a chegada dos itens transacionados ao país do comprador. O primeiro termo é o Delivered At Terminal (DAT), "Entregue no Terminal", que determina a entrega da mercadoria pelo vendedor, após ser descarregada, sendo colocada à disposição em terminal indicado no porto. Não apenas, o exportador também fica encarregado de assumir os riscos de transporte do produto e sua inclusão no terminal.

O termo nomeado como Delivered At Place (DAP), "Entregue no local", assinala a entrega das mercadorias pelo exportador, no momento em que estão disponibilizadas ao comprador no local de destino indicado, após serem descarregadas. A propósito, o vendedor é encarregado em arcar com os riscos de transporte até o ponto final determinado.

Por derradeiro, oportuno mencionar o Delivered Duty Paid (DDP), no qual o exportador tem obrigação de cuidar dos custos e dos riscos presentes durante 0 transporte dos produtos até o local de destino, ainda mais, é incumbido do desembaraço dos itens para a exportação e importação, vale dizer, deve pagar qualquer imposto relativos às duas operações comerciais.

Para a escolha do termo, importante que as partes considerem algumas peculiaridades do objeto negociado e as condições da transação a ser efetuada. Neste ponto, a doutrina indica a necessidade de observação da conveniência financeira e da competitividade, a facilidade na contração do transporte e do seguro, as restrições ou incentivos governamentais, a estrutura logística, a redução de obrigações de vendedores e compradores, bem como a data ou período para a entrega da mercadoria (LUNARDI, 2001, p. 37-41).

Acima de tudo, faz-se necessário, quando da elaboração do contrato de compra e venda, a indicação clara de que o negócio jurídico é regido pelo Incoterms e qual versão é adotada, a fim de que produzam todos seus efeitos.

Assim, com base no histórico, nos fundamentos e nas espécies do Incoterms e, principalmente, na necessidade de uniformização das regras que tratam do comércio internacional, destaca-se que o objetivo central dos termos em análise recai sobre a facilitação da operação mercantil entre países, a partir da eliminação das más interpretações de cláusulas contratuais, de costumes e das condições da 


\section{Personalidade Acadêmica Homenageada:}

\section{Florisbal de Souza Del'Olmo (Professor Convidado - UNICURITIBA)}

lei aplicada.

Nota-se, no geral, que o regramento privado é marcado por inúmeras vantagens e benefícios, isto porque, caminha no sentido de abarcar, de forma única, uma variedade de condições para o sucesso da atividade comercial. Neste contexto, o primeiro aspecto positivo é evidenciado pela simplificação dos processos mercantis, por meio da descrição clara da responsabilidade entre as partes, assim como o afastamento de divergências legislativas que, em grande parte, propiciam interpretações diversas e desentendimentos entre vendedor e comprador.

A vantagem inicial, portanto, é possibilitar uma interpretação uniforme aos procedimentos do comércio internacional, objetivando o afastamento das principais dificuldades enfrentadas no relacionamento entre as partes, tais como: as incertezas se as leis do próprio país são aplicáveis aos contratos; as dúvidas ocasionadas por informações imprecisas; e, por fim, os obstáculos provocados pela diversidade de interpretações (NETO, 2010, p. 219).

Ainda quanto à questão legal, vale citar que os termos internacionais ensejam, também, a eliminação de lacunas da lei aplicada em cada situação, pois têm o condão de apresentar condições completas do modo correto de transação entre as partes, além disto, traça limites de responsabilizações a serem aplicadas e possíveis riscos de prejuízo.

Em terceiro lugar, o Incoterms possibilita a redução dos custos de compra e venda, uma vez que confere maior segurança e clareza jurídica, desta forma, restringe as cláusulas do negócio jurídico e, por conseguinte, beneficia financeiramente os dois comerciantes.

Em vista da sua natureza flexível e dinâmica, os termos internacionais possuem facilidade de adaptação com as novas e mutáveis práticas comerciais, destarte, conduzem a sua eficiência contratual. Aliás, em virtude da frequente transformação das atividades mercantis, o Incoterms também é suscetível de modificações, visando sempre estar alinhado com o comércio globalizado e com os avanços da tecnologia.

Finalmente, os regramentos apresentados pela Câmara Internacional do Comércio se mostram mais efetivos que as leis nacionais, considerando a existência 


\section{Personalidade Acadêmica Homenageada:}

\section{Florisbal de Souza Del'Olmo (Professor Convidado - UNICURITIBA)}

de previsões de condições pontuais e suficientes para a transação entre os países.

Em contrapartida, embora os aspectos negativos dos termos analisados não sejam tão explícitos quanto seus benefícios, ressaltam-se as principais desvantagens demonstradas na sua aplicação. Registra-se, inicialmente, a não obrigatoriedade de utilização dos termos, em segundo lugar, existe o escopo limitado do instituto (LUÉVANO, 2013, p. 8), de modo que não regule todos os aspectos do contrato de venda, apenas trabalhe com as obrigações de entrega e questões relacionadas (custos, seguro, embalagens dos produtos e outras questões incidentais).

Desta maneira, embora prescreva várias condições completas para o sucesso das transações mercantis entre países, não é suficiente a ponto de prever a infinidade de situações existentes no decorrer da cadeia da atividade comercial. $\mathrm{Na}$ verdade, continua inexistente a regulação acerca de aspectos comuns a todos os contratos de venda, como incidentes que afetam a validade dos contratos, a transferência de propriedade, impossibilidade de execução, deturpação, deveres do vendedor em relação ao despejo ou as qualidades dos bens, obrigação do comprador de pagar, impedimentos contra o desempenho causado por eventos imprevistos e inevitáveis, bem como a violação e recursos por quebra contratual, como aponta Coetzee (2010, p. 78).

Cabe salientar, outrossim, que o Incoterms não se caracteriza como contrato em si mesmo, tampouco como instrumento legal, o que, de certa forma, indica a necessidade de sua implementação e maior aderência pelas partes, pois acaba sendo visto como mero termo contratual.

Nota-se, na terceira posição, a questão relativa às interpretações diversas feitas pelas partes, o que gera a frustração dos fins dos termos internacionais, dada a alteração feita no conteúdo original.

Enfim, se por um lado as novas fontes da Lex mercatoria representam o adiantamento da uniformização das regras comerciais, por outro, como dito previamente, os termos internacionais apontam a urgência de uma complementação feita lei que rege o contrato, quer dizer, a lei utilizada no negócio jurídico deve estar atrelada com o Incoterms, para este tenha força de atuação, e mais, deixe de ser 


\section{Personalidade Acadêmica Homenageada:}

\section{Florisbal de Souza Del'Olmo (Professor Convidado - UNICURITIBA)}

\section{considerado apenas como condição contratual.}

Nesta linha, a doutrina também pontua a necessidade de combinação com outros instrumentos internacionais de harmonização, como os Princípios do UNIDROIT ou da CISG, tendo como consequência a construção de uma "Leiquadro" que pode facilitar vendas internacionais eficazes (COETZEE, 2010, p.83).

Aliás, em que pese haja a emergência do aprimoramento e complementação das regras internacionais, os Tribunais dos Estados Unidos, Rússia e da Argentina já têm adotado o entendimento pela aplicação automática do Incoterms nos contratos comerciais, em razão de sserem bastante conhecidos no mundo mercantil (COETZEE, 2010, p. 80-82). Esta jurisprudência tem respaldo na previsão do artigo 9º, (2), da CISG, que dispõe sobre a aplicação automática de usos amplamente conhecidos no âmbito da prática mercantil internacional (ORGANIZAÇÃO DAS NAÇÕES UNIDAS, 2010).

Caminhando em sentido semelhante, a Alemanha e a França têm incorporado os termos internacionais com base nos costumes do comércio exterior, além da frequente utilização deles. Já a secretaria da UNCITRAL entende que o Incoterms pode substituir as disposições da Convenção, já que são condições baseadas em usos comuns dos mercadores.

De todo modo, embora a jurisprudência dos mencionados países direcionese para o reconhecimento do Incoterms como regulamento único, com força de regra, ainda há muito que fazer pelo seu incremento, a fim de que não seja visualizado somente como cláusula contratual, mas um modelo completo que abrange todas as situações de compra e venda de bens e, assim, estimula, torna simples e menos custosa a transação entre os países.

\section{CONCLUSÃO}

Por todo o exposto, conclui-se pela grande relevância que a inserção do Incoterms possui no âmbito da regulamentação do comércio internacional. Isto porque, após a evolução das práticas mercantis e de suas normas, surgiram 


\section{Personalidade Acadêmica Homenageada:}

\section{Florisbal de Souza Del'Olmo (Professor Convidado - UNICURITIBA)}

elementos da Globalização, como é o caso do rompimento de fronteiras, da padronização de regulamentos, de origem particular, e, em especial, da necessidade de harmonização de regras. Nesta perspectiva, os termos internacionais de compra e venda possibilitam a unificação pretendida, ademais, oferecem maior segurança e previsibilidade durante a transação mercantil entre países.

Mais que isto, observando o Incoterms como uma das fontes da nova Lex mercatoria, o instituto tem o condão de afastar os desentendimentos frequentes entre exportador e importador, no que tange à interpretação das leis aplicáveis ao contrato, bem como aos usos e costumes de cada país. Para mais, os termos criados pela Câmara Internacional do Comércio também propiciam a redução de custos da compra e venda, estabelecem direitos e obrigações às partes, além de fixar seguros, quando houver dano ou prejuízo ao produto comercializado.

Entretanto, ainda com todas as vantagens oferecidas, o Incoterms permanece como cláusula contratual, diante do não reconhecimento como contrato, sequer como instrumento legal, pois falta força jurídica que traga a sua aplicação automática. Assim, torna imprescindível o aprimoramento de seu conteúdo e da sua estrutura, a partir da sua utilização combinada com outras fontes privadas da Lex mercatoria, ou com regras abarcadas em tratados e convenções internacionais.

Acrescente-se, também, a necessidade da mudança de entendimento jurisprudencial dos tribunais de outros países, a fim de que reconheçam a aplicação automática do Incoterms, quer pela alteração de sua natureza, quer pela admissão do conteúdo previsto no artigo 9º, (2), da CISG, como já fazem as cortes dos Estados Unidos, Rússia, Argentina, Alemanha e França.

Logo, o sucesso dos termos internacionais do comércio está atrelado à aplicação automática, além do incremento de sua essência, tornando possível a unificação das fontes que regem a mercancia exterior e, por conseguinte, facilitando os negócios jurídicos entre pessoas e empresas de países distintos.

\section{BIBLIOGRAFIA}

AMARAL, Antonio Carlos Rodrigues. Direito do comércio internacional: aspectos 
Personalidade Acadêmica Homenageada:

Florisbal de Souza Del'Olmo (Professor Convidado - UNICURITIBA)

fundamentais. 2 ed. São Paulo: Lex Editora, 2006.

CÁRNIO, Thaís Cíntia. Contratos internacionais: teoria e prática. São Paulo: Editos Atlas S.A, 2009.

CARVALHO, Maria Auxiliadora de; SILVA, César Roberto Leite da. Economia Internacional. São Paulo: Editora Saraiva, 2000.

COETZEE, Juana. Incoterms and the lex mercatoria. n. 12. Curitiba: Cadernos da Escola de Direito e Relações Internacionais da Unibrasil, 2010. p. 70-83.

ENGELBERG, Esther. Contratos internacionais do comércio. 2.ed. São Paulo: Editora Atlas S.A, 1997.

HUBERMAN, Leo. A história da riqueza do homem. 16 ed. Rio de Janeiro: Zahar Editores, 1980.

INTERNATIONAL CHAMBER OF COMMERCE. Incoterms Rules. Disponível em: $<$ https://iccwbo.org/resources-for-business/incoterms-rules/>. Acesso em 10 de outubro de 2018.

LUÉVANO, Julio Hernández et al. Incoterms y su importancia en las actividades comerciales. n. 186. México: Observatorio de la Economía Latinoamericana, 2013.

LUNARDI, Angelo Luiz. Incoterms 2000: Condições Internacionais de Compra e Venda. 2 ed. São Paulo: Aduaneiras, 2001.

NETO, José Cretella. Contratos Internacionais do Comércio. Campinas: Millenium Editora, 2010.

ORGANIZAÇÃO DAS NAÇÕES UNIDAS. Convenção Convenção das Nações Unidas sobre Contratos para a Venda Internacional de Mercadorias (2010). Disponível em: <https://www.uncitral.org/pdf/english/texts/sales/cisg/V1056997CISG-e-book.pdf>. Acesso em 14 de outubro de 2018.

PIRES, Adilson Rodrigues. Práticas abusivas no comércio internacional. Rio de Janeiro: Forense, 2001.

ROMERO, José Maria Gondra. La moderna lex mercatoria y la unificación del Derecho del Comercio Internacional. Madrid: Revista de Derecho Mercantil, 1973.

ROSSETTI, José Paschoal. Introdução à economia. 20 ed. São Paulo: Editora Atlas S.A, 2014. 